\title{
Evaluation the role uterine artery Doppler Indices in prediction of abnormal uterine bleeding in intrauterine contraceptive device users
}

\author{
Ashraf Mohamed Safwat Ibrahim ${ }^{1 *}$ and Dina Husseiny Salama ${ }^{1}$
}

1* Assistant Professor of Obstetrics and Gynecology, Faculty of Medicine, Tanta University. Egypt

*Corresponding author: Nareman Elhamamy, Assistant Professor of Obstetrics and Gynecology, Faculty of Medicine, Tanta University. Egypt

Received date: May 24, 2020; Accepted date: May 31, 2020; Published date: June 08, 2020

Citation: Nareman Elhamamy, Ahmed M. Hagras (2021) Evaluation the Role Uterine Artery Doppler Indices in Prediction of

Abnormal Uterine Bleeding in Intrauterine Contraceptive Device Users. J Women Health Care Issues, 4(4); Doi:10.31579/2642-9756/067

Copyright: (C) 2020 Ashraf Mohamed Safwat Ibrahim, This is an open access article distributed under the Creative Commons Attribution License, which permits unrestricted use, distribution, and reproduction in any medium, provided the original work is properly cited.

\section{Abstract}

Contraceptive intrauterine device (IUD) is a successful method of contraception which has been used for more than 30 years. However, the most common copper intrauterine device (CIUD) related side effect is excessive uterine bleeding. The menstrual blood loss is commonly doubled after the insertion of CIUD. Frequently, the menstrual blood may be excessive to the extent of causing iron deficiency anemia. Women with heavy menstruation may not be able to tolerate the use of CIUD. Within one year, approximately $10-15 \%$ of women remove the CIUD because of this annoying problem.

The objectives of our study were to evaluate the correlation between abnormal uterine bleeding in IUD users and uterine artery Doppler [pulsitility index (PI); Resistant index (RI)] using transvaginal ultrasound and Doppler.The study included 120 women from obstetrics and gynecology department Hospital. ,divided into three groups:

- Group I included 40 women using coipper intrauterine device (TCu-380A) and complaining of menorrhagia or menometrorrhagia.

- Group II included 40 women using CIUD and not complaining of abnormal uterine bleeding.

- Group III included 40 women complaining of vaginal discharge or requesting CIUD insertion, and not complaining of abnormal uterine bleeding as a control group.

All fullfil the inclusion and exclusion criteria
1- History was obtained.
2- Examination was done:
3- Routine investigations:

Ultrasound examination:

Blood flow indices of the uterine artery:

The results of this work were:-

As regard to Doppler findings, it was noted that RI was significantly lower in group I in comparison to group II and group III and Pulsitility index (PI) followed the same pattern as RI.

We can conclude that PI and RI were significantly lower in women with IUD-induced abnormal bleeding than in those using IUD without complaining of abnormal vaginal bleeding. That detection of PI and RI in the uterine artery could be used to identify patients at risk of developing excessive bleeding after copper IUD insertion. Key Words: gynecology; uterine artery Doppler; abnormal uterine bleeding

\section{Introduction:}

The Intrauterine Device (IUD) is the most widely used reversible form of contraception in the world [1].

Menstrual disorders are a common indication for medical visits among women of reproductive age and heavy menstrual bleeding affects up to $30 \%$ of women throughout their reproductive lifetime. AUB may be defined as any variation from the normal menstrual cycle, and includes changes in regularity and frequency of menses, in duration of flow, or in amount of blood loss [2].

Ultrasound is the imaging modality+ of choice for the female pelvis. It is widely available, has broad acceptance by patients and is relatively inexpensive. High-resolution imaging of transvaginal ultrasound provides high diagnostic accuracy for pelvic pathology [3].

Color Doppler ultrasonography to confirm the hypothesis that CIUDinduced bleeding is secondary to an increase in the uterine blood flow (as indicated by decreased PI and RI in uterine artery). They constructed the ROC curves for PI and RI to choose the cutoff values for discriminating between women using CIUD and complaining of menorrhagia or menometrorrhagia and women using CIUD and not complaining of abnormal uterine bleeding. These are a plot of the true positive rate (sensitivity) against the false positive rate (1-sensitivity) for the different possible cutpoints of a diagnostic test. In the first case (PI) they obtained a ROC area of 0.829 and we chose 2.07 as the cutoff point, the value of 
the area showed the accuracy of the test. In the second case (RI) we obtained a ROC area of 0.804 and we chose 0.7 as the cutoff point, the value of the area showed the accuracy of the test. PI has sensitivity $84.4 \%$ and specificity $83.3 \%$ in the detecting women with CIUD complaining of abnormal uterine bleeding and RI has sensitivity $78.1 \%$ and specificity $80 \%$ in the detecting women with CIUD complaining of abnormal uterine bleeding. So, transvaginal color Doppler can be used to identify women at risk of developing abnormal uterine bleeding after CIUD insertion [4]. Aim of the work

The present study aimed at using color Doppler ultrasonography in prediction of abnormal uterine bleeding in women after IUD insertion.

\section{Patients and methods}

This study was a prospective clinical study including women who have been wearing an CIUCD, presenting to Obstetrics and Gynecology Department, in one of the hospitals in Cairo, Egypt, from may 2018 to may 2019.

Study populations:

The study included 120 women. Sample size was calculated using Epi-Info ${ }^{\circledR}$ version 6.0 software, assuming a power of $80 \%$ and an $\alpha$-error of $0.5 \%$.

Included women were divided into three groups:

- Group I included 40 women using copper intrauterine device (TCu380A) and complaining of menorrhagia or menometrorrhagia.

- Group II included 40 women using CIUD and not complaining of abnormal uterine bleeding.

- Group III included 40 women complaining of vaginal discharge or requesting CIUD insertion, and not complaining of abnormal uterine bleeding as a control group.

Inclusion criteria:

1. Regularly menstruating women before CIUD insertion.

2. Age between 20 and 35 years.

3. Hormonal treatment not taken at least 2 months before the study.

4. Non-steroidal anti-inflammatory not taken 24 hours before the examination.

Exclusion Criteria:

1. Pregnancy.

2. Nulligravida.

3. Present or past history of pelvic inflammatory disease.

4. Other causes of abnormal uterine bleeding such asadenomyosis and the presence of pelvic pathology as ovarian cysts, pelvic endometriosis, endometrial polyps and uterine fibroids.

5. Medicated IUD.

\section{Methods:}

\section{Detailed history:}

Clinical examination:

C-Routine investigations:

- Blood group and $\mathrm{Rh}$ factor.

-Complete blood count.

-Random blood sugar.

Ultrasound examination:

All included women had a transvaginal ultrasound performed after instructing the patient to evacuate the bladder. The ultrasound set used was (7.5 MHz transvaginal transducer with color Doppler facilities (Voluson 530-D Medison).

Measurements of dimension of the uterus (sagittal, transverse) sections were performed in addition to comment on: (a) Position.

(b) Endometrial thickness measured in sagittal section.

(c) Myometrial fibroids or adenomyosis.

(d) Endometrial polyps, thickness and irregularities.

(e) Adnexa and any abnormalities as ovarian cysts.

(f) Comment on IUCD: including site, displacement, partial expulsion, partial perforation, embedding:

i) The IUCD was detected by its echogenicity compared to the normal endometrium. The sonographic appearance of an IUCD is determined by its shape and composition. Intrauterine contraceptive devices are made of a combination of plastic and metal (copper). The metal causes a "reverberation artifact" a series of parallel lines that become progressively weaker posterior, when the IUCD is parallel to the ultrasound beam Plastic tubing is displayed as 2 parallel lines representing an entrance and an exit shadow. A normally positioned IUCD lies in the midline of the endometrial canal, equidistant from the uterine margins.

ii) After identification of the IUCD within the uterine cavity the distance between the top of the vertical arm of the device to the endo-myometrial junction (IUCD myometrium) was measured.

\section{Blood flow indices of the uterine artery:}

Transvaginal probe is placed in the anterior fornix, moved laterally to visualize the paracervical vascular plexus, Color Doppler is turned on and the uterine artery is identified as it turns cranially to make its ascent to the uterine body.

Measurements are taken at this point, before the uterine artery branches into the arcuate arteries. The same process is repeated on the

contralateral side.

Care should be taken not to insonate the cervicovaginal artery (which runs from cephalad to caudad) or the arcuate arteries. Velocities over $50 \mathrm{~cm} / \mathrm{s}$ are typical of uterine arteries, which can be used to differentiate this vessel from arcuate arteries.

Blood flow indices of the uterine artery; the Pulsatility Index (PI) and the Resistance Index (RI) were calculated according to the following equations: $\mathrm{PI}=(\mathrm{A}-\mathrm{B}) /$ mean, and $\mathrm{RI}=(\mathrm{A}-\mathrm{B}) / \mathrm{A}$, where $\mathrm{A}$ is the peak systolic, $\mathrm{B}$ is the end-diastolic Doppler shift, and mean is the mean maximum Doppler shift frequency taken over the cardiac cycle. The mean PI and RI were calculated by combining three waveforms of the left and right uterine artery and were used for subsequent statistical analysis.

Data were entered checked and analyzed using Epi-Info version 6 and SPP for Windows version 8 [5].

For all above mentioned statistical tests done, the threshold of significance is fixed at $5 \%$ level (p-value).

The results was considered:

- Significant when the probability of error is less than $5 \%(\mathrm{p}<0.05)$.

- Non-significant when the probability of error is more than $5 \%(\mathrm{p}>$ $0.05)$.

- Highly significant when the probability of error is less than $0.1 \%$ (p $<0.001)$.

The smaller the p-value obtained, the more significant are the results. 


\section{Results}

This prospective clinical study included 120 women who have been wearing an IUD for at least 6 months, presenting to Outpatient Gynecologic Clinic

The study included 120 women, divided into three groups:

- Group I included 40 women using coipper intrauterine device (TCu380A) and complaining of menorrhagia or menometrorrhagia.

- Group II included 40 women using CIUD and not complaining of abnormal uterine bleeding.

- Group III included 40 women complaining of vaginal discharge or requesting CIUD insertion, and not complaining of abnormal uterine bleeding as a control group.
There was no significant difference between studied groups as regard demographic data in our study, there were no significant statistical differences between the studied groups concerning age, parity and duration of IUD use table $\mathbf{1 , 2}$.

There were no statistically significant differences between groups concerning between groups concerning uterus dimensions and endometrial thickness measure by TVS. RI was significantly lower in women of group I than in women of groups II and III ( $p<0.001)$. PI was significantly lower in women of group I than in women of groups II and III ( $p<0.001)$ (table 3$)$. At a cutoff value of 2, PI has a sensitivity of $90 \%$ and specificity of $92.5 \%$ and RI at a cutoff value of 0.7 has a sensitivity of $80 \%$ and specificity of $87.5 \%$ in predicting induced uterine bleeding (table 4).

\begin{tabular}{|c|c|c|c|c|c|c|c|c|}
\hline & & $\begin{array}{c}\text { Group I }(n= \\
40)\end{array}$ & \multicolumn{2}{|c|}{ Group II $(n=40)$} & \multicolumn{2}{|c|}{$\begin{array}{l}\text { Control } \\
(\mathrm{n}=40)\end{array}$} & $\mathbf{F}$ & $\mathbf{P}$ \\
\hline \multicolumn{2}{|c|}{$\begin{array}{c}\text { Mean } \pm \text { SD } \\
\text { Range }\end{array}$} & $\begin{array}{c}29.1 \pm 4.9 \\
20-35\end{array}$ & \multicolumn{2}{|c|}{$\begin{array}{c}28.4 \pm 4.4 \\
23-35\end{array}$} & \multicolumn{2}{|c|}{$\begin{array}{c}28.8 \pm 6.1 \\
20-35\end{array}$} & 0.07 & $\begin{array}{l}0.9 \\
(\mathrm{NS})\end{array}$ \\
\hline \multirow[t]{2}{*}{ Parity } & \multicolumn{2}{|c|}{ Group I $(n=40)$} & \multicolumn{2}{|c|}{ Group II $(n=40)$} & \multicolumn{2}{|c|}{$\begin{array}{l}\text { Control } \\
(\mathrm{n}=40)\end{array}$} & \multirow[t]{2}{*}{$\mathbf{X}^{2}$} & \multirow[t]{2}{*}{$\mathbf{P}$} \\
\hline & No & $\%$ & No & $\%$ & No & $\%$ & & \\
\hline$\leq 2$ & 30 & 75 & 32 & 80 & 26 & 65 & \multirow{2}{*}{0.48} & 0.7 \\
\hline$>2$ & 10 & 25 & 8 & 20 & 14 & 35 & & (NS) \\
\hline \multicolumn{2}{|c|}{$\begin{array}{c}\text { Duration of use } \\
\text { (months) }\end{array}$} & $\underset{40)}{\text { Group } I}(n=$ & \multicolumn{2}{|c|}{ Group II $(n=40)$} & \multicolumn{2}{|c|}{$\begin{array}{l}\text { Control } \\
(n=40)\end{array}$} & $\mathbf{F}$ & $\mathbf{P}$ \\
\hline \multicolumn{2}{|c|}{ Mean \pm SD } & $49.9 \pm 22$ & \multicolumn{2}{|c|}{$44.1 \pm 18.6$} & \multicolumn{2}{|c|}{$48.8 \pm 18$} & 0.4 & 0.62 \\
\hline \multicolumn{2}{|c|}{ Range } & $6-80$ & \multicolumn{2}{|c|}{$6-80$} & \multicolumn{2}{|c|}{$6-80$} & & (NS) \\
\hline
\end{tabular}

Table 1: Difference between the studied groups concerning demographic data

\begin{tabular}{|c|c|c|c|c|c|c|c|c|}
\hline & \multicolumn{2}{|c|}{ Postpartum } & \multicolumn{2}{|c|}{ Post-abortion } & \multicolumn{2}{|c|}{ Postmenstrual } & \multirow{2}{*}{$\mathbf{X}^{2}$} & \multirow[b]{2}{*}{$\mathbf{p}$} \\
\hline & No & $\%$ & No & $\%$ & No & $\%$ & & \\
\hline Group I & 20 & 50 & 4 & 10 & 16 & 40 & 0.39 & $\begin{array}{l}0.82 \\
(\mathrm{NS})\end{array}$ \\
\hline Group II & 22 & 55 & 2 & 5 & 16 & 40 & 0.11 & $\begin{array}{l}0.94 \\
(\mathrm{NS})\end{array}$ \\
\hline Control & 20 & 50 & 2 & 5 & 18 & 45 & - & - \\
\hline
\end{tabular}

Table 2: Difference between the studied groups concerning timing of IUD insertion (analysis using Chi-square test)

\begin{tabular}{|c|c|c|c|c|c|}
\hline & Group I Mean \pm SD & $\begin{array}{l}\text { Group II Mean } \pm \\
\text { SD }\end{array}$ & $\begin{array}{c}\text { Control } \\
\text { Mean } \pm \text { SD }\end{array}$ & F & p \\
\hline $\begin{array}{c}\text { Uterus length } \\
(\mathbf{m m})\end{array}$ & $76.4 \pm 9.6$ & $81.7 \pm 14.1$ & $82.6 \pm 12.6$ & 1.49 & 0.23 (NS) \\
\hline Width (mm) & $48.5 \pm 13.8$ & $49.1 \pm 12.7$ & $46.9 \pm 11.68$ & 0.15 & $0.85(\mathrm{NS})$ \\
\hline $\begin{array}{c}\text { Endometrial } \\
\text { thickness (mm) }\end{array}$ & $8.1 \pm 1.1$ & $7.9 \pm 1.6$ & $7.6 \pm 2$ & 0.48 & $0.61(\mathrm{NS})$ \\
\hline RI & Group IMean \pm SD & Group II Mean \pm SD & Control Mean \pm SD & F & P \\
\hline Mean \pm SD & $0.69 \pm 0.07$ & $0.79 \pm 0.1$ & $0.82 \pm 0.12$ & 15.69 & $<0.001$ (HS) \\
\hline Range & $0.59-0.8$ & $0.6-0.89$ & $0.61-0.9$ & & \\
\hline PI & Group I Mean \pm SD & $\begin{array}{c}\text { Group II Mean } \\
\pm \text { SD }\end{array}$ & $\begin{array}{c}\text { Control } \\
\text { Mean } \pm \text { SD }\end{array}$ & F & P \\
\hline Mean \pm SD & $1.9 \pm 0.05$ & $2.2 \pm 0.269$ & $2.3 \pm 0.25$ & 13.7 & $<0.001$ \\
Range & $1.65-2.42$ & $1.87-2.63$ & $1.89-2.65$ & & $($ HS) \\
\hline
\end{tabular}

Table 3: Difference between the studied groups concerning US data (analysis using one-way anova test)

\begin{tabular}{|c|c|c|c|c|c|c|}
\hline & Cutoff & Sensitivity (\%) & Specificity (\%) & PPV (\%) & NPV (\%) & Accuracy (\%) \\
\hline PI & 2 & 90 & 92.5 & 85.7 & 94.9 & 91.7 \\
\hline
\end{tabular}


87.5

89.7

\section{ROC Curve}

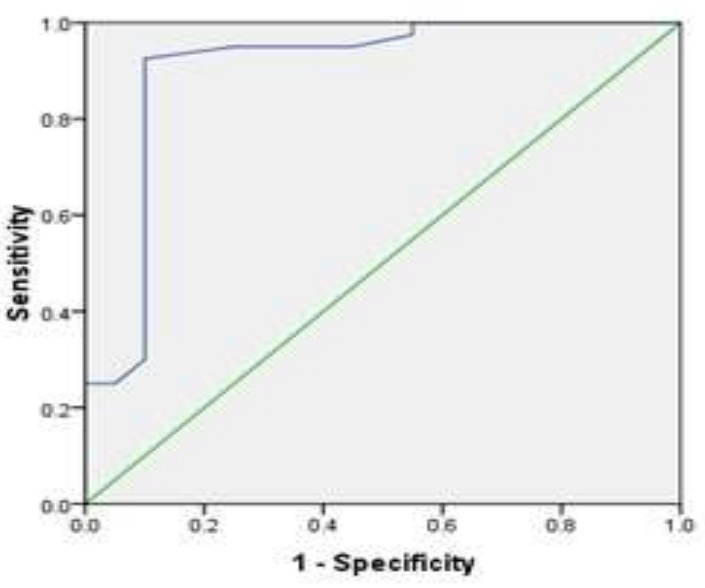

Diagonal segments are produced by ties. 


\section{Discussion}

The objectives of our study were to evaluate the prediction between abnormal uterine bleeding in IUD users and uterine artery Doppler [pulsitility index (PI); Resistant index (RI)] using transvaginal ultrasound and Doppler.

We found in our study that RI and PI were significantly lower in women using CIUD and complaining of abnormal uterine bleeding (indicating increase in the uterine blood flow) than in women using CIUD and not complaining of abnormal uterine bleeding and women not using CIUD.

In our study, there were no significant statistical differences between the studied groups concerning age, parity and duration of IUD use.

Our results are in agreement with another study that stated that there were no significant differences between patients in the three groups with respect to age, parity, and body mass index (BMI).Also In this study, there were no statistically significant differences between groups concerning uterus dimensions and endometrial thickness measure by TVS (4).

Our results are in agreement with study that., stated during his work on the levonorgestrel IUD that there is no correlation between endometrial thickness and days of bleeding or spotting observed in both groups [6].

On the other hand in our study, RI and PI were significantly lower in women of group I (women using CIUD and complaining of abnormal uterine bleeding) than in women of group II (women using CIUD and not complaining of abnormal uterine bleeding) and group III (control group) $(\mathrm{p}<0.001)$.

Our results are correlated with Momtaz et al. (1994). They measured the PI and RI of uterine arteries in 68 women, including 44 using intrauterine contraceptive device and 24 control women who were not using a method of contraception. Both the PI and RI were significantly lower in women with CIUD-induced bleeding than in those using CIUD and not complaining of abnormal vaginal bleeding. In addition, there were no statistically significant differences in PI and RI between women using CIUD without complaining of abnormal vaginal bleeding and women in the control group. They reported that the PI was less than 2 in women with CIUD-induced bleeding, while the mean PI in women using IUD without complications was 2.38 with the lowest PI being 1.98 (7).

Frajndlich et al. (2000) measured resistance and pulsatility indices in 101 women, 74 of whom were using an intrauterine contraceptive device, and 27 controls, who were not using any contraceptive method. The intrauterine contraceptive device users were divided into three groups: those with normal bleeding $(\mathrm{n}=34)$; those with abnormal uterine bleeding without medication $(\mathrm{n}=16)$; and those with abnormal bleeding corrected with use of prostaglandin inhibitors $(n=24)$. The resistance and pulsatility values were significantly lower in the group of women using intrauterine contraceptive devices who had abnormal bleeding than in all other groups. A pulsatility index of less than 2 may be associated with a higher risk for development of intrauterine contraceptive device-induced bleeding [8].

Hurskainen et al. (1999) measured the PI of uterine arteries, arcuate arteries, and radial arteries in 60 spontaneously menstruating women complaining of menorrhagia. Menstrual blood loss was measured by the alkaline hematin method. A significant inverse correlation was found between uterine artery PI and the amount of menstrual blood loss, suggesting that women with lower uterine flow impedance bleedmore [9].

Yigit et al. (2009) measured PI, RI, and systole/diastole ratio(S/D) in the uterine artery and its myometrial branches in 28 patients before and after the insertion of CIUD. They reported that the PI and S/D values in the uterine artery increased significantly after the insertion of the CIUD ( $p$ $<0.05$ ). Patients with increased bleeding scores after insertion of CIUD had significantly lower uterine artery PI compared with those without increased bleeding scores $(\mathrm{p}<0.05)$. They concluded that low uterine artery PI values recorded in the early phase of the menstrual cycle in patients with a CIUD were associated with an increased bleeding risk [10].

Another study conducted a study on 93 women divided into three groups. In group I; 25 women were complaining of menorrhagia and seven women were complaining of menometrorrhagia. In group II; the causes of attendance to outpatient clinic were vaginal discharge (12 patients), inability to feel the threads of CIUD (10 women) and request of CIUD removal ( 8 women). In group III; 20 women were requesting CIUD insertion and 11 women were complaining of vaginal discharge. They found that the PI and RI were significantly lower in women in group I compared to women in group II and group III. There were no statistically significant differences in PI and RI between women in group II and group III [4].

In contrast to our results, De Souza and Geber (2006) measured the PI and RI in 100 patients before and 30 days after the insertion of CIUD, no statistically significant changes in PI and RI values were detected (11). Jamenez et al. (2008) reported that there were no statistically significant differences in PI and RI between women with IUD-induced bleeding and women using IUD with normal menstruation [12].

There are several mechanisms explaining the association between the increase in the uterine blood flow (as indicated by decreased PI and RI in the uterine artery) and the increase in menstrual blood loss. It has been suggested that metrorrhagia, may be caused by increased uterine secretion of prostanoids leading to an increase in vascularity, vascular permeability, and inhibition of platelet activity [13].

Concerning the effect of IUD on the biosynthesis of prostaglandins in the endometrium, El-Sahwi et al. (1987) observed a significant rise in both PGF2a and PGE2 concentrations in the uterine wash 3 months after IUD insertion but not in users

who had used an IUD for at least 2 years; the temporary post-insertion rise in prostaglandin concentrations coincided with the phase of increased bleeding and pain (14), Xin et al. (2009) found that there was overexpression of mRNA and protein of COX-2 enzyme leading to overproduction of prostaglandins in the endometrium after the insertion of CIUD [15].

Other vasoactive substances may also be involved, including nitric oxide (NO) which is a potent vasodilator produced by the vascular endothelium. $\mathrm{NO}$ is present in the human endometrium and myometrium. There is evidence that NO may play a part in acute and chronic inflammation [16]. 
The introduction of an intrauterine device into the uterine cavity induces a foreign body reaction in the surrounding endometrium. NO is present in the foreign body inflammatory reaction around loosened joint replacement implants. Thus, it is possible that IUD also induces NO synthesis in the surrounding tissue. There is also a connection between NO synthesis and prostaglandin synthesis. NO directly interacts with cyclo-oxygenase, which is responsible for prostaglandin synthesis and causes an increase in enzymatic activity [17].

There are also other possible mechanisms explaining the association of the PI of uterine artery with menstrual blood loss. Women with menorrhagia show a significant increase in endothelial cell proliferation, reflecting disturbed angiogenesis. It is possible that there are also other vascular abnormalities resulting from disturbed angiogenesis. In abnormal vessels, poor contractibility and dysfunction of the haemostatic system may cause menorrhagia and decreased impedance [18].

Xin et al. (2004) reported that the expression of vascular endothelial growth factor (VEGF) and its receptor, kinase insert domain containing receptor (KDR) and microvessel density (MVD) were increased in the endometrium after using CIUD [19].

Lee et al. (1997) studied 96 women for localization of IUCD by threedimensional ultrasound showing that transvaginal sonography using multiplanar views has proven to give full visualization of the complete IUCD in $95 \%$ of patients [20].

In other study that evaluated the effects of a copper IUD on uterine artery blood flow in 21 women with regular menstrual cycles using copper IUDs. The patients had transvaginal sonography with color Doppler flow imaging to measure the PI in the uterine arteries during the midluteal phase and on the first day of menstruation, after which the IUD was inserted. Three months later, the patients were examined again on the corresponding cycle days. Patients with IUD-associated dysmenorrhea had an increased Pulsatility Index (PI) when compared with asymptomatic patients. They did not find significant changes in uterine artery blood flow after the insertion of the IUD during menstruation or in the midluteal phase. However, in patients with increased IUD-related pain during menstruation, there was a decrease in the PI after IUD insertion. The decrease in the mean PI was present in all 5 patients. They concluded

that the copper IUD does not induce any major changes in the resistance of uterine artery blood flow, although during menstruation in patients with increased menstrual pain after IUD insertion, there seems to be a decrease in the uterine artery PI [21].

Jimenez et al. (2008) used power Doppler analysis as well as Resistance Index (RI) and Pulsatility Index (PI) to quantify the sub endometrial micro vascularization and uterine artery blood flow in patients with IUDinduced side effects (LNG-IUS and T Cu 380A). They concluded that sub endometrial vascularization was increased in patients with IUD-induced side effects, controlling for IUD type, age and parity. This method could be used as a prognostic factor to better evaluate those patients at risk of developing severe dysmenorrhea and/or excessive bleeding after IUD insertion (12).

In other hand other study used color Doppler ultrasonography to confirm the hypothesis that CIUD-induced bleeding is secondary to an increase in the uterine blood flow (as indicated by decreased PI and RI in uterine artery). They constructed the ROC curves for PI and RI to choose the cutoff values for discriminating between women using CIUD and complaining of menorrhagia or menometrorrhagia and women using CIUD and not complaining of abnormal uterine bleeding. These are a plot of the true positive rate (sensitivity) against the false positive rate (1sensitivity) for the different possible cutpoints of a diagnostic test. In the first case (PI) we obtained a ROC area of 0.829 and we chose 2.07 as the cutoff point, the value of the area showed the accuracy of the test. In the second case (RI) we obtained a ROC area of 0.804 and we chose 0.7 as the cutoff point, the value of the area showed the accuracy of the test. PI has sensitivity $84.4 \%$ and specificity $83.3 \%$ in the detecting women with CIUD complaining of abnormal uterine bleeding and RI has sensitivity $78.1 \%$ and specificity $80 \%$ in the detecting women with CIUD complaining of abnormal uterine bleeding. So, transvaginal color Doppler can be used to identify women at risk of developing abnormal uterine bleeding after CIUD insertion [4].

On the basis of these observations and our present study, it is possible that CIUD induces changes in the production of prostaglandins and stimulates angiogenesis in the endometrium leading to an increase in the uterine blood flow.

\section{Conclusion}

The results of our study confirm the hypothesis that there is an increase in the uterine blood flow (indicated by decreased PI and RI in the uterine artery) in patients with CIUD-induced abnormal uterine bleeding. The uterine artery doppler could be used to identify patients at risk of developing excessive bleeding after copper IUD insertion.

However, since the sample number is small, it might be difficult to confirm these results and give recommendations upon them. It is also proposed that further research would be done on this topic to confirm or negate these results

\section{References}

1. Nelson A.; Grimes D.; Arias R.; et al. (2006): Intrauterine copper contraceptive: update and opportunities. OBG. Managemenkt available at. www.obgmanagment.com.

2. Munro MG (2010): Abnormal uterine bleeding, Cambridge: Cambridge University Press.

3. American College of Obstetricians and Gynecologists (2012): Ultrasonography. ACOG Technical Bulletin Number 191. Int J Gynaecol Obstet; 45(2): 175-180.

4. Munro MG, Critchley HO, Broder MS, et al. (2011): FIGO classification system (PALM-COEIN) for causes of abnormal uterine bleeding in nongravid women of reproductive age, Int J Gynaecol Obstet.; 113: 3-13.

5. Dean F (2006): Statistical methods in scientific researches. European Jou

6. Perchick GB, Jabbour HN (2003): Cyclooxygenase-2 overexpressioninhibits cathepsin D-mediated cleavage of plasminogen to the potent antiangiogenic factor angiostatin. Endocrinology; 144: 5322-88.rnal of Scientific Research; 14(3). 
7. Momtaz M, Zayed M, Rashid K, et al. (1994): Doppler study of the uterine artery in patients using an intrauterine contraceptive device. Ultrasound Obstet Gynecol; 4: 231.

8. Farquhar C, Ekeroma A, Furness S, et al. (2003): A systematic review of transvaginal ultrasonography, sonohysterography and hysteroscopy for the investigation of abnormal uterine bleeding in premenopausal women, Acta Obstet Gynecol Scand; 82: 493 - 504.

9. Hurskainen R, Teperi J, Paavonen J, et al. (1999): Menorrhagia and uterine artery blood flow. Hum Reprod; 14: 186-189.

10. Yigit N, Kacar M, Yigit H, et al. (2009): The effects of copper contraceptive intrauterine device on the uterine blood flow: A prospective transvaginal Doppler study. J Clin Ultrasound; 37(7): 380-384.

11. De Souza MA, Geber S (2006): Doppler color flow analysis of the uterine arteries before and after intrauterine device insertion: a prospective study. J Ultrasound Med; 25: 153 .

12. Jimenez MF, Vetori D, Fagundes PA, et al. (2008): Subendometrial microvascularization and uterine artery blood flow in IUD-induced side effects (levonorgestrel intrauterine system and copper intrauterine device). Contraception; 78(4): 324-327.

13. Smith OP, Jabbour HN, Critchley HO (2007): Cyclooxygenase enzyme expression and $\mathrm{E}$ series prostaglandin receptor signalling are enhanced in heavy menstruation. Hum Reprod; 22(5): 1450-1456.
14. El-Sahwi S, Toppozada M, Kamel M, et al. (1987): Prostaglandins and cellular reaction in uterine flushings. I. Effect of IUD insertion. Adv Contracept; 3: 291-302.

15. Xin ZM, Cao LM, Xie QZ, et al. (2009): Effects of the copper intrauterine device on the expression of cyclooxygenase- 1 and -2 in the endometrium. Int $\mathbf{J}$ Gynaecol Obstet; 105(2): 166-168.

16. Laroux FS, Lefer DJ, Kawachi S, et al. (2000): Role of nitric oxide in the regulation of acute and chronic inflammation. Antioxid Redox Signal; 2(3): 391-396.

17. Roberto da Costa RP, Costa AS, Platek R, et al. (2008): Actions of a nitric oxide donor on prostaglandin production and angiogenic activity in the equine endometrium. Reprod Fertil Dev; 20: 674-683.

18. Mints M, Blomgren B, Palmblad J (2007): Expression of vascular endothelial growth factor receptor-3 in the endometrium in menorrhagia. Int J Mol Med; 19(6): 909913.

19. Xin ZM, Xie QZ, Cao LM, et al. (2004): Effects of intrauterine contraceptive device on expression of vascular endothelial growth factor, kinase insert domain-containing receptor and microvessel density in endometrium. Zhonghua Fu Chan Ke Za Zhi; 39(11): 771-775.

20. Lee A, Eppel W, Sam C, et al. (1997): Intrauterine device localization by three-dimensional transvaginal sonography. Ultrasound Obstet Gynecol; 10: 289-292.

21. Jutras M , Cowan D. (2006): Abnormal bleeding in the climacteric. J Obstet Gynecol Clin North Am; 17: 409-425

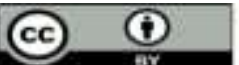

This work is licensed under Creative Commons Attribution 4.0 License

To Submit Your Article Click Here: Submit Article

DOI:10.31579/2642-9756/067
Ready to submit your research? Choose Auctores and benefit from:

* fast, convenient online submission

* rigorous peer review by experienced research in your field

* rapid publication on acceptance

* authors retain copyrights

* unique DOI for all articles

* immediate, unrestricted online access

At Auctores, research is always in progress.

Learn more https://www.auctoresonline.org/journals/women-health-careand-issues 